\title{
Quantitative measurement of contagion effects during a Global Financial Crisis: Evidence from selected countries
}

\author{
Nirosha Hewa Wellalage, Sazali Abidin and Lei Wang \\ Department of Finance, Waikato Management School, \\ University of Waikato, Private Bag 3105, Hamilton 3240, New Zealand \\ Tel: +(647) 838-4196,E-mail: nirosha@waikato.ac.nz
}

\begin{abstract}
This paper investigates the existence and extent of contagion effects among international stock markets during the Global Financial Crisis (GFC), and if these financial contagion effects exist, it explores the differences of contagion effects in different sub-periods of pre, during, and post Global Financial Crisis. In a financial definition, the "domino effect" among international stock markets has been referred to as contagion, which draws much academic attention nowadays. Investigating contagion effects among stock markets helps us to study the inner relationship among global stock markets and to further prevent the devastating impact of similar catastrophes such as the Global Financial Crisis.
\end{abstract}

Keywords: Global Financial Crisis, Financial contagion effects, micro, small and medium enterprises, India, Credit constraints 
Wellalage, Abidin \& Wang, Quantitative measurement of contagion effects during a Global Financial Crisis: Evidence from selected countries

\section{INTRODUCTION}

This paper mainly aims to address whether the contagion effects among international stock markets exist in the US Subprime Mortgage crisis, and if the financial contagion existed, what are the differences of contagion effects in each of the sub-periods.

Masson (1998) concludes there are three types of contagion, including monsoonal effect, spillover effect and pure contagion. Monsoonal effect emphasises the attack which can affect the macro economy of all countries. It can be measured by the change of macro-economic variables. This paper takes CPI, Current account to GDP, Domestic Credit to GDP, Interest Rate, Money Supply to Total Foreign Reserve $\left(\mathrm{M}_{2}\right.$ to Reserve) and Real Effective Exchange Rate (REER) into consideration. The spillover effect explains how the crisis of one country can attack other countries, and generally there are two ways for a country to affect another: financial spillover and trade spillover. Since this paper sets stock index return as a dependent variable, only the trade spillover effect will be analysed. Moreover, the trade spillover effect is measured by a coefficient called Trade $_{i}$, which estimates the trade linkage between a specific country i and the "ground zero." Lastly, pure contagion always happens in analogous countries. If one country is in crisis, the intention of avoiding losses causes investors to stop investing in countries which are economically, politically or geophysically similar to the "ground zero" country. Thus, these behaviours cause other analogous countries to undergo financial crisis as well. This paper uses distances from a specific country to the USA on an economic-political coordinate axis and geographical coordinate axis to evaluate the effects of economic-political similarity and the effects of geographical similarity.

\section{DATA}

This paper collects data from three main sources: Datastream, The World Bank and the International Monetary Fund (IMF). It firstly gets daily price indices of S\&P500 (USA), TSX60 (Canada), FTSE100 (UK), DAX60 (Germany), NIKKEI255 (Japan), KOSPI200 (Korea), SSE50 (China), CNX500 (India), ASX200 (Australia) and NZX50 (New Zealand). This paper selects ten countries, including the USA, the UK, Germany, Japan, Korea, China, India, Australia and New Zealand. These countries are the most representative countries of the Americas, Europe, Asia and Oceania. Studying them can explain the global influence of the US Mortgage Crisis and further reveal the international contagion channel of the crisis.

For this paper, the research target is the US Subprime mortgage crisis in 2008, which caused a international global financial crisis afterwards. In order to compare and analyse contagion effects among stock markets in the whole process of the financial crisis, the sample periods should include pre-crisis period, during crisis period (local breakout period and international breakout period) and after crisis period. Based on the above reasons, the whole period should be broken into four sub-periods, including pre-crisis period (2006), local breakout period (2007), international breakout period (2008) and after-crisis period (2009.).

Screening of variables are based on the following criteria:

1. Choosing daily stock price indices rather than monthly data: Daily data is more precise than monthly data. In modern financial markets, the exchange of information is very fast. The transmission of information will affect the financial contagion significantly. Thus, high-frequency trading data is required in this paper.

2. Selection of stock market in each country: Most of the target countries have more than one stock market. In order to simplify analysis, this paper only chose the most representative market in each country; for example, the choosing of the stock index of Shanghai stock exchange (SSE50) rather than index of the Shenzhen stock exchange, since the Shanghai stock exchange is the largest stock market in China. Most blue chips are traded in this stock market. Thus, SSE50 is more representative than other stock indices in Chinese stock markets. The reason to choose S\&P500 rather than the Dow-Jones Average Index is that S\&P500 consists of more companies than DJIA. Thus, the study of S\&P500 is more appropriate for this paper. 
Wellalage, Abidin \& Wang, Quantitative measurement of contagion effects during a Global Financial Crisis: Evidence from selected countries

3. Using the daily return of stock price indices as variable: the calculated formula is that

$$
R_{t}=\left(P_{t}-P_{t-1}\right) / P_{t-1}
$$

$R_{t}$ is the daily return of stock indices; $P_{t}$ is the closing price of stock indices for day $\mathrm{t} ; P_{t-1}$ is the closing price of stock indices for day $\mathrm{t}-1$.

However, different countries have different holidays. During holidays, stock markets will not trade. Thus, it will lead to a problem that at the same time, there is a Non-Match Error of trading data. There are two methods to deal with this problem. The first one involves using moving average to replace missing data. The second one involves deleting missing data. In order to simplify calculation, this paper uses the second method to process missing data. After treating data, the sample size for each country is 1065 .

In terms of macro-economic variables, this paper uses monthly data. More specifically, Inflation rate, Current account to GDP and Interest Rate are obtained from Datastream. Domestic Credit, Money Supply to Total Foreign Reserve ( $\mathrm{M}_{2}$ to Reserve) and Real Effective Exchange Rate (REER) came from The World Bank. Moreover, the trading data is from the IMF (2011). Based on the discussion of Glick and Rose (1999), a country which is first attacked in a financial crisis can be regarded as "first victim" or "ground zero." In the subprime mortgage crisis, the USA is believed to be "ground zero." Trade $e_{i}$ measures the trade linkage between a specific country i and the "ground zero," which can be calculated as follows (Glick \& Rose, 1999):

$$
\left.\operatorname{Trade}_{i} \equiv \sum_{k}\left\{\left[\frac{x_{0 k}+x_{i k}}{x_{0}+x_{i}}\right] *\left[1-\left|\frac{x_{i k}-x_{0 k}}{x_{i k}+x_{0 k}}\right|\right)\right]\right\}
$$

Here, $x_{i k}$ is the aggregate bilateral export from country i to country $\mathrm{k}$, and $x_{i}$ is the total aggregate bilateral export from country $\mathrm{i}$, while $x_{0 k}$ is the aggregate bilateral export from ground zero to country $\mathrm{k}$ and $x_{0}$ is the total aggregate bilateral export from ground zero. For the purpose of simplifying calculation, in this paper, country $\mathrm{k}$ denotes emerging countries and developed countries. Larger Trade $_{i}$ implies greater trade completion between ground zero and country $i$.

Then, the economic and political data are received from the global economic freedom index of The Heritage Foundation and Wall Street Journal and the geographical data comes from CSGnetwork. Specifically, the economic freedom index consists of property rights, freedom from corruption, fiscal freedom, government spending, business freedom, labour freedom, monetary freedom, trade freedom, investment freedom and financial freedom. Among all of them, property rights, freedom from corruption and government spending are regarded as political indices, while fiscal freedom, business freedom, labour freedom, monetary freedom, trade freedom, investment freedom and financial freedom are believed to be economic indices. This paper sets average economic indices as $\mathrm{X}$ and average political indices as $\mathrm{Y}$ to establish an economic-political coordinate axis. In terms of geographical data, this paper regards latitude as $\mathrm{X}$ and longitude as $\mathrm{Y}$ to set a geographical coordinate axis. Each country has its specific location on these coordinate axes.

In the subprime mortgage crisis, the USA was the first victim. Thus, this paper calculates distances between the USA and other countries on the economic-political coordinate axis and geographical coordinate axis. The equations can be written as: $\quad D(e p)_{i}=\ln \left(\sqrt{\left(x_{e p i}-x_{e p 0}\right)^{2}+\left(y_{e p i}-y_{e p 0}\right)^{2}}, \quad D(g)_{i}=\right.$ $\ln \left(\sqrt{\left(x_{g i}-x_{g 0}\right)^{2}+\left(y_{g i}-y_{g 0}\right)^{2}}\right.$

Here, $D(e p)_{i}$ and $D(g)_{i}$ represent the distances from s specific country i to "ground zero" on economicpolitical coordinate axis and geographical coordinate axis respectively. $x_{e p i}, x_{e p 0}, y_{e p i}$ and $y_{e p 0}$ are $\mathrm{x}$ and $\mathrm{y}$ values of country $\mathrm{i}$ and "ground zero" on the economic-political coordinate axis. $x_{g i}, x_{g 0}, y_{g i}$ and $y_{g 0}$ are $\mathrm{x}$ and y values of country i and "ground zero" on the geographical coordinate axis. 
Wellalage, Abidin \& Wang, Quantitative measurement of contagion effects during a Global Financial Crisis: Evidence from selected countries

\section{METHODOLOGY}

Static Correlation analysis method

Correlation coefficient is the most common way to measure linear correlation (dependence) between two variables. The higher value of $r$ means stronger correlation between markets. Meanwhile, if the correlation coefficient $r$ is negative, the movement of one market will negatively influence another market. The model is explained as follow:

$$
\mathrm{r}=\operatorname{corr}(\mathrm{m}, \mathrm{n})=\frac{\operatorname{cov}_{(m, n)}}{\sigma_{m} * \sigma_{n}}=\frac{\sum_{i=1}^{k}\left(m_{i}-E(m)\right) *\left(n_{i}-E(n)\right)}{\sqrt{\sum_{i=1}^{k}\left(m_{i}-E(m)\right)^{2}} * \sum_{i=1}^{k}\left(n_{i}-E(n)\right)^{2}}
$$

Where $\mathrm{m}$ denotes market $\mathrm{m}, \mathrm{n}$ represents market $\mathrm{n}$ and $\mathrm{i}$ means trading days.

\section{Vector auto-regression (VAR)}

Even though correlation analysis can measure linear correlation between stock markets, the Vector autoregression is a more proper way to analyze time-varying relationship among stock markets which is the most successful and flexible models for the analysis of multivariate time series.

The VAR model commonly can be regarded as a way of conducting granger causality test and impulse response function.

Granger causality test

Granger causality test is utilized to check whether one time series can be used to predict another. In other words, if past values of $y$ helps to predict $x$, then $y$ granger causes $x$ (Granger, 1969).

\section{DCC-MVGARCH model}

The Dynamic Conditional Correlation Multivariate GARCH (DCC-MVGARCH) model is specially designed to examine volatility of multivariate time series. This model includes two steps. Firstly, a series of univariate GARCH should be constructed. Secondly, by using univariate GARCH, DCC parameters and correlation coefficient will be estimated (Engle, 2002).

\section{RESULTS}

\section{$\underline{\text { Static Correlation analysis }}$}

Looking at the whole period, with the degeneration of the financial crisis, correlation coefficients between stock markets increase dramatically. ${ }^{1}$ For example, the correlation coefficient between the US stock market and German stock market rose from 0.5588 in 2006 to 0.696 in 2009. The correlation coefficient between the US stock market and Australian stock market increased from 0.0462 to 0.165 during the whole period. Although the correlation coefficient between the US stock market and New Zealand stock market is low, it still has huge growth. All these phenomena prove that no matter where the stock market is and what regulations it has, it will be affected by other stock markets in a financial crisis. Based on the definition of the World Bank, if the correlation coefficient remains steady during the whole period, it can be viewed as co-movement of stock markets. However, if there is an excess increase in correlation coefficient, it can be treated as contagion. Thus, through the correlation analysis, it proves that the contagion existed.

However, the correlation analysis only measures linear relationships among stock markets. Since the stock indices are time-varying, the correlation coefficient among stock markets is changing all the time. Thus, it is

\footnotetext{
${ }^{1}$ Correlation tables are available upon request from the authors
} 
Wellalage, Abidin \& Wang, Quantitative measurement of contagion effects during a Global Financial Crisis: Evidence from selected countries

necessary to construct a Vector Auto-regression to investigate the time-varying characteristics of stock correlation and to further explain the time-varying relationships among stock markets.

\section{VAR model}

ADF test

According to ADF test.in both sub-periods and the whole period, all test statistics are statistically significant at 0.01 and the null hypothesis is rejected. It illustrates that all stock indices during each period are stable. Thus, without establishing a difference equation, the Vector auto-regression can be constructed.

Granger causality test

According to Granger test tt can be clearly seen that with the worsening of the financial crisis, more countries have causality relationships with other countries and the cross-country infection effects become more obvious. Causality relationships existed in all sub-periods, but they are more visible when the global financial crisis happened.

\section{DCC-MVGARCH analysis}

\section{DCC-MVGARCH correlation}

As introduced in the methodology section, the DCC-MVGARCH model is constructed by two processes. Firstly, two univariate GARCH $(1,1)$ models are established to obtain variances. Based on the ARCH test, all stock indices are believed to have autoregressive conditional heteroscedastic (ARCH) effects. Thus, $\operatorname{GARCH}(1,1)$ can be constructed; then, a multivariate model is constructed, which can be used to estimate DCC parameters and dynamic conditional correlations between stock indices. The results in DCC-MVGARCH correlation is supported by following figures of pair-wise dynamic correlations. The dynamic conditional correlations of USA-Japan, USA-Korea, USA-Australia and USA-New Zealand fluctuate randomly. It shows that the subprime crisis cannot pose huge influence on the pair-wise correlation coefficients between them. However, from following figures, the movements of pair-wise correlations suggest the crisis in the USA is transmitted to Canada, the UK, Germany and India, which proves the existence of contagion effect. Meanwhile, it shows that with the worsening of the financial crisis, the correlation coefficients become higher. Although the dynamic conditional correlation coefficients of USA-Japan, USA-Korea, USA-Australia and USA-New Zealand move stochastically, based on static correlation analysis and the Granger causality test, the results suggest that the US subprime mortgage crisis indeed spread to Japan, Korea, Australia and New Zealand. Thus, this paper does further tests on DCC correlations on UK-Japan, UK-Australia, UK-New Zealand.

From the above figures, the crisis in the UK had a huge influence on dynamic conditional correlations of UKJapan, UK-Australia, and UK-New Zealand. All correlations show that in the global financial tsunami period, the time-varying correlations reached their peak. When the global economy recovers, the correlation coefficients decrease. It is the same with the movements of correlations between USA-Canada, USA-UK, USA-Germany and USA-India, which proves the contagion effects of internationally. Although the dynamic conditional correlation coefficients of USA-Japan, USA-Australia and USA-New Zealand do not have excess increases, it cannot say the US subprime mortgage crisis has no influence on Japan, Australia and New Zealand. Since the contagion effects between UK-Japan, UK-Australia, UK-New Zealand are proven, through the stock markets of UK, the US subprime mortgage crisis was transmitted to Japan, Australia and New Zealand. Not only the UK, but also Canada and Germany all acted as intermediaries of the US subprime mortgage crisis. The crisis can spread from the USA to target countries directly. It also can be transmitted to more countries through the UK, Canada and Germany. Thus, both linear contagion and cross contagion existed in the subprime mortgage crisis.

\section{Robustness check}

In order to check the validity of findings, this paper employs T-test and Z-test to test the existence of financial contagion. T-test is used to find out differences of mean and Z-test is utilised to check differences of median. 
Wellalage, Abidin \& Wang, Quantitative measurement of contagion effects during a Global Financial Crisis: Evidence from selected countries

In May 2008, the subprime mortgage attacked most of international community and the worst time was believed to have started at that time. Thus, this paper regarded May $20^{\text {th }}, 2008$ as the breakout point of international shock. The breakout point of the shock divides the whole sample period into pre shock period and after shock period. This paper calculates the means, medians, and standard deviations of dynamic conditional correlation coefficients for all the pair-wise countries in each period. Then it uses T-test and Z-test to find out whether means and medians of each pair-wise country remain stable in different periods. The null hypothesis of T-test is that means of two periods are the same and the null hypothesis of Z-test is that medians of two periods are the same. If $\mathrm{P}$ values of T-test and Z-test are smaller than 0.05 , the null hypotheses should be rejected, which explains that contagion effects can be found.

\section{CONCLUSION}

In order to investigate contagion effects among international countries, this research selects the US subprime mortgage crisis as the study target, from 2006 to 2009. Firstly, the statistic correlation model, VAR model and DCC-MVGARCH model suggest that correlation coefficients among stock markets in the pre-crisis period are low but increase dramatically during crisis. Thus, it proves the contagion effects indeed exist in the US Subprime Mortgage crisis. Then, from the Granger causality test and Impulse response function, it can be found that when the financial crisis is severe, the contagion effects are obvious. Meanwhile, when the economy recovers, the influential power of financial contagion would be lower. It may due to the feedback effects. The US subprime crisis derived from the USA. It not only had negative impacts on the US economy but also spread to more countries and caused international financial crisis. In return, the devastating crisis spread back from other countries to the USA. This vicious circle accelerates effects of financial contagion and the global economic recession.

Thirdly, DCC-MVGARCH model suggests that in the US Subprime Mortgage crisis, some developed countries, such as the UK, acted as intermediaries. Through them, the financial crisis was transmitted to more countries. It proves that both linear contagion and cross contagion can be found in the US subprime mortgage crisis. It also supports the existence of contagion effects between developed and emergent markets.

Lastly, the panel weighted regression tests explain that monsoonal effect, spillover effect and pure contagion existed in the US subprime mortgage crisis. It shows that overall global economy, trade linkage and economicpolitical similarities are transmission channels of financial contagion.

\section{REFERENCES}

Glick, R., \& Rose, A. K. . (1999). Contagion and trade: Why are currency crises regional? Journal of international Money and Finance, 18(4), 603-617.

Masson, P. R. (1998). Contagion-monsoonal effects, spillovers, and jumps between multiple equilibria. International Monetary Fund 